\title{
PIRMINĖS DISMENORĖJOS ITTAKA SU SVEIKATA SUSIJUSIAI GYVENIMO KOKYBEI
}

\author{
Deimantė Krutulyte் ${ }^{1}$, Lina Varaneckienè ${ }^{2}$ \\ ${ }^{1}$ Lietuvos sveikatos mokslu universiteto Medicinos fakultetas, ${ }^{2}$ Amberclinic
}

Raktažodžiai: pirminè dismenoreja, su sveikata susijusi gyvenimo kokybè, skausmas.

\begin{abstract}
Santrauka
Pirminè dismenoreja (skausmingos mènesinès, nesant organinès dubens organų patologijos) yra viena iš dažniausių ginekologinių ligų. Nors mokslinèje literatūroje gausu ịrodymų apie pirminès dismenorejjos neigiamą įtaką su sveikata susijusiai gyvenimo kokybei, neretai šis sutrikimas pakankamai rimtai neicvertinamas ar net laikomas normalia ménesiniu ciklo dalimi. Straipsnyje plačiau aptariamas šios ligos poveikis moters psichikos sveikatai, fizinei ir socialinei gerovei.
\end{abstract}

\section{İvadas}

Su sveikata susijusi gyvenimo kokybe (toliau - GK) atspindi, kaip žmogus suvokia ligos paveiktas savo fizines, psichikos bei socialines galimybes ir reaguoja $i$ jas [1]. Terminas aprépia ir objektyvuji asmens funkcinès būklès vertinimą. M. Muldoon ir bendraautoriai remiasi paprastesne samprata: sveikata yra psichikos ir fizinè, vertinama objektyviai ir subjektyviai, todèl yra 4 pagrindiniai GK vertinimo komponentai - objektyvusis protinis ir fizinis pajègumas bei subjektyvioji dvasinè ir fizinè būklè [2].

Žinoma, kad skausmas, ypač lètinis, yra vienas iš dažniausių veiksnių, neigiamai veikiančių GK [3]. Pirminè dismenoreja (toliau - PD) - apatinés pilvo dalies spazminis skausmas, pasireiškiantis iš karto prieš ir (ar) per menstruacijas, nesant organinès dubens organų patologijos. PD turi ir lètiniam, ir ūmiam skausmui būdingų bruožų: numatoma pradžia, cikliškai pasikartoja, bet trunka trumpai [4]. Manoma, kad PD yra dažniausia moterų ginekologinè problema, nepaisant tautybės ar amžiaus [5]. Tikslus ligos paplitimas nežinomas (kai kurių autorių duomenimis, 45-95 procentų) [6], nes neretai skausmas suvokiamas kaip normali mėnesinių eigos dalis ir nesikreipiama ị specialistus [7].

Tyrimo tikslas - apžvelgti mokslinèje literatūroje PD problematiką ir ịtaką moters GK, plačiau aptariant poveikị psichikos, socialinei ir fizinei sveikatai.

\section{Tyrimo medžiaga ir metodai}

Atlikta mokslinès literatūros anglų kalba apžvalga ir analizè, naudojantis PubMed, ScienceDirect ir Google Scholar informacinèmis bazėmis.

\section{Tyrimo rezultatai}

PD poveikis su sveikata susijusiai GK. S. Iacovides ir bendraautorių tyrimas turi išskirtini privalumą: $\mathrm{PD}$ poveikis GK vertintas esant skausmui (per menstruacijas), ir jo nesant (folikulinèje fazèje). Pirmają ciklo dieną (dažniausiai esant intensyviausiai dismenorejai) moterys, turinčios PD požymių, surinko mažiau Q-LES-Q gyvenimo kokybės ir pasitenkinimo juo klausimyno balų, negu kontrolinės grupès tiriamosios ir mažiau, lyginant su jomis folikulineje (beskausmèje) fazèje. Nesant skausmo, sveikujų ir turinčiujų PD požymių tiriamujų GK rodikliai nesiskyrè. Vadinasi, skausmo malšinimas turètų padèti subalansuoti GK skirtumus, atsirandančius menstruacijų metu, ir išvengti ilgalaikių komplikacijų. Kaip vieną iš PD terapijos efektyvumo vertinimo rodiklių, autoriai siūlo naudoti GK tyrimą [8]. PD poveikio su sveikata susijusiai gyvenimo kokybei schema pateikiama 1 paveiksle.

Poveikis psichikos sveikatai. Daugumoje Z. Bajalan ir kt. sisteminejje apžvalgoje nagrinètų mokslinių publikacijų buvo rasta sąsaja tarp PD ir depresijos bei nerimo sutrikimų [9]. Ryšys aiškinamas ịvairių organizmo sistemų sąveika: nuo neuroendokrininių priežasčiu [10] iki įsijautrinimo skausmui. Pasak S. Iacovides ir bendraautorių, kas mènesį patiriamos skausmingos menstruacijos gali sukelti centrinę sensitizaciją, todèl PD patiriančios moterys ị skausmą reaguoja jautriau, negu sveikosios [11]. Kita vertus, skausmas yra ne tik sensorinè patirtis. Suvokdamos, kad dismenoreja pasikartos kito ciklo metu (PD iš dalies yra lètinè liga), pacientès patiria prieštaringas emocijas, prisidedančias prie 
psichologinio distreso ir sutrikimų, tokių, kaip nerimas ir depresija, vystymosi [12].

Poveikis poilsiui. Remiantis subjektyviais pacientų ir objektyviais duomenimis, nustatyta, kad skausmas yra glaudžiai susijęs su prasta miego kokybe [13, 14]. Ne išimtis ir PD, kurios metu miego kokybę gali bloginti ir šalutiniai simptomai, kaip pykinimas, vėmimas, viduriavimas ar raumenų mèšlungis [15].

S. Iacovides ir kt. miego laboratorijoje tyrè patiriančiąsias PD folikulinès fazès viduryje (neskausminga stadija) ir 2 mėnesinių ciklų pirmą dieną (skausmo stadija), kartą joms davę diklofenako kalio (nesteroidinis vaistas nuo uždegimo, toliau - NVNU, analgetikas), o kitą - placebo. Remiantis subjektyviais ir polisomnografijos duomenis, tyrejai suformulavo išvadas: skausmo stadijoje vartojančios placebą tiriamosios skundèsi blogesne nuotaika, nustatytas prastesnis miego efektyvumas (viso miego laiko ir laiko, praleisto lovoje, santykis), mažesnis REM ir didesnis 1 fazès miego kiekis, lyginant su neskausminga stadija. Skausmo stadijoje vartojant diklofenako kali, lyginant su placebu, padidejjo miego efektyvumas ir REM kiekis, atitinkamai sumažejo 1 fazès miego. Pagerèjo ir subjektyvieji miego vertinimo

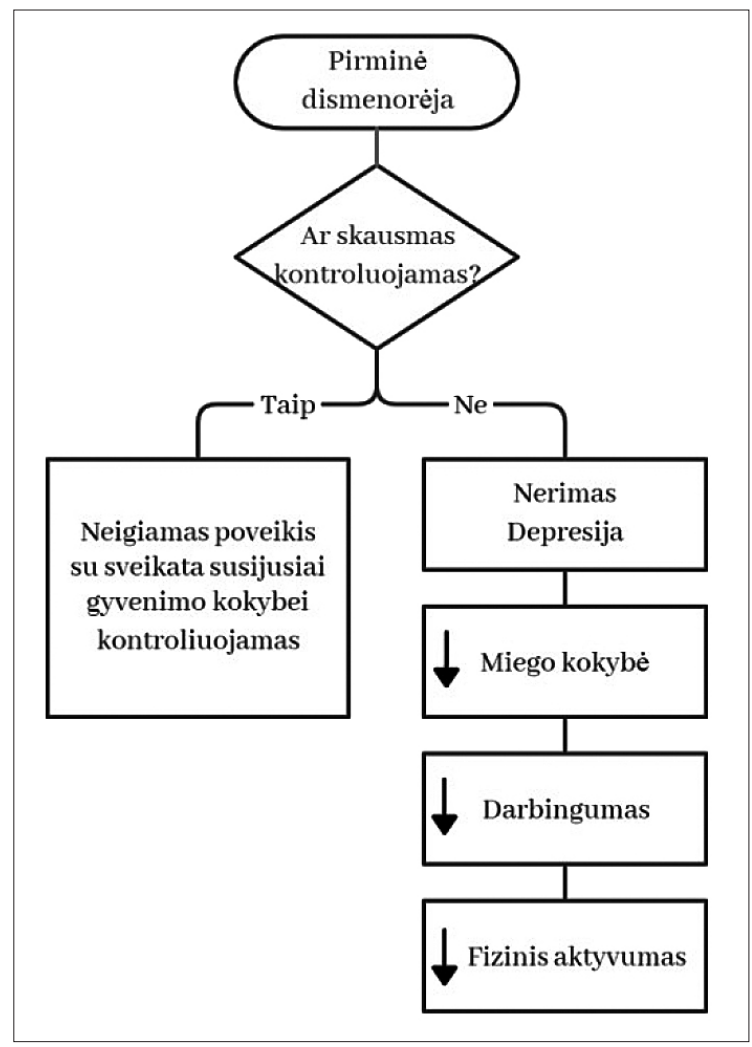

1 pav. PD poveikis su sveikata susijusiai gyvenimo kokybei rodikliai [16]. Gauti rezultatai panašūs ị tyrimo, kuriame moterys stebètos 3 ciklu pirmosiomis dienomis: per pirmas menstruacijas vaistų nevartojo (bazinis stebejjimas), o per likusias vieną kartą gavo melatonino (gerina miegą, galimai slopina skausmą), o kitą - meloksikamo (NVNU, analgetikas). Lyginant su bazinio stebejjimo rezultatais, melatonino arba meloksikamo vartojimas padidino miego trukmę ir jo efektyvumą, sutrumpèjo miego latentiškumas, sumažèjo prabudimų skaičius [17]. Svarbu pabrèžti, kad dèl skausmo prastejja miego kokybè, o visaverčio poilsio stoka dar labiau didina jautrumą skausmui [18]. Dèl šio dvigubo poveikio PD patiriančios moterys dažnai dienos metu skundžiasi mieguistumu, dirglumu, sumažejjusiu darbingumu ar prasta nuotaika.

Poveikis darbingumui. Išsilavinimas ir karjera yra neginčijama gyvenimo kokybès dalis. S. Hailemeskel ir kt. tyrime apie 88 proc. respondenčių įžvelgé neigiamą PD įtaką akademinei veiklai. Pavyzdžiui, 80 proc. tiriamuju dèl skausmo neatvyko ị mokymosi ịstaigą. Užsièmimų metu mokymasis nebuvo pakankamai efektyvus, nes daugiau nei pusè merginų skundèsi sunkumu susikoncentruoti, 15 proc. blogiau pasirodè atsiskaitymų metu, o 21 proc. nesugebėjo atlikti namų darbų [19]. Akivaizdi teigiama koreliacija tarp dismenorejos intensyvumo ir absenteizmo - dèl mažo ar vidutinio skausmo praleidžiama mažiau pamokų, negu dèl didelio. Stipresnis skausmas labiau veikia gebejimą susikoncentruoti [20]. Kitame tyrime analizuojamas praleistų mokymosi dienų skaičius: 46 proc. merginų nepasirodè pusę ar 1, 36 proc. $2-3$ ir 18 proc. daugiau nei 4 dienas [21]. Manoma, kad moterys JAV dèl PD kasmet praleidžia apie 600 milijonų darbo valandų arba šalis praranda 2 milijardus dolerių [22].

Poveikis fiziniam aktyvumui. Ribotas judejimas ir iš to kylantis diskomfortas - dar viena PD pasekmé. Dažnai fiziniam aktyvumui įvertinti naudojami ịvairūs klausimynai ar dienoraščiai. Šios priemonès grindžiamos individualiais potyriais ir nèra visiškai patikimos. I. Chantler ir kt. rémėsi alternatyviu metodu - aktigrafija (neinvazinis būdas stebèti žmogaus aktyvumo-poilsio ciklus). Tirtos 12 merginų esant PD ir 12 - jos nesant (nè viena reguliariai nesportavo, pagrindinè fizinè veikla - vaikščiojimas), ant klubo segèjo aktyvumo sekikli 3 dienas esant menstruacijoms ir 3 dienas jų nesant. Paaiškejjo, kad PD grupès fizinis aktyvumas menstruacijų metu sumažèjo 40 proc., o kontrolinès išliko toks pat, kaip ir ịprastinèmis dienomis (nors kai kurios iš jų ir juto silpną skausmą menstruacijų metu). Nustatyta, kad fizinį pasyvumą lemia ne menstruacijos, bet jų metu patiriamas nekontroliuojamas skausmas [23].

\section{Išvados}

PD turi neigiamą poveikị GK, ypač jei patiriamas skausmas nekontroliuojamas. Svarbu išsiaiškinti, ar taikomas arba 
pačių pasirinktas PD gydymo būdas yra efektyvus, kad būtų išvengta nerimo ar depresijos ir nereikètų atsiriboti nuo kasdienès socialinès (mokykla, darbas) ir fizinès veiklos.

\section{Literatūra}

1. Staškutė I. Su sveikata susijusios gyvenimo kokybès samprata, stebėsenos ir vertinimo metodai bei reikšmè sveikatos politikoje. Sveikatos politika ir valdymas, 2014(6):7-19. https://doi.org/10.13165/SPV-14-1-6-01

2. Muldoon MF, Barger SD, Flory JD, Manuck SB. What are quality of life measurements measuring? BMJ 1998;316(7130):542. https://doi.org/10.1136/bmj.316.7130.542

3. Souza CA, Oliveira LM, Scheffel C, Genro VK, Rosa V, Chaves MF, et al. Quality of life associated to chronic pelvic pain is independent of endometriosis diagnosis a cross-sectional survey. Health Qual Life Outcomes 2011;9(1):41.

https://doi.org/10.1186/1477-7525-9-41

4. Baker FC, Driver HS, Rogers GG, Paiker J, Mitchell D. High nocturnal body temperatures and disturbed sleep in women with primary dysmenorrhea. Am J Physiol Metab 1999;277(6):E1013-21.

https://doi.org/10.1152/ajpendo.1999.277.6.E1013

5. Patel V, Tanksale V, Sahasrabhojanee M, Gupte S, Nevrekar P. The burden and determinants of dysmenorrhoea: a populationbased survey of 2262 women in Goa, India. BJOG An Int J Obstet Gynaecol 2006;113(4):453-63.

https://doi.org/10.1111/j.1471-0528.2006.00874.x

6. Unsal A, Ayranci U, Tozun M, Arslan G, Calik E. Prevalence of dysmenorrhea and its effect on quality of life among a group of female university students. Ups J Med Sci 2010;115(2):138-45. https://doi.org/10.3109/03009730903457218

7. Wong LP. Attitudes towards dysmenorrhoea, impact and treatment seeking among adolescent girls: a rural school-based survey. Aust J Rural Health 2011;19(4):218-23.

https://doi.org/10.1111/j.1440-1584.2011.01213.x

8. Iacovides S, Avidon I, Bentley A, Baker FC. Reduced quality of life when experiencing menstrual pain in women with primary dysmenorrhea. Acta Obstet Gynecol Scand 2014;93(2):213-7. https://doi.org/10.1111/aogs.12287

9. Bajalan Z, Moafi F, Moradi Baglooei M, Alimoradi Z. Mental health and primary dysmenorrhea: a systematic review. J Psychosom Obstet Gynecol 2019;40(3):185-94.

https://doi.org/10.1080/0167482X.2018.1470619

10. Westling AM, Tu FF, Griffith JW, Hellman KM. The association of dysmenorrhea with noncyclic pelvic pain accounting for psychological factors. American Journal of Obstetrics and Gynecology 2013;209(5):422.e1-422.e10. https://doi.org/10.1016/j.ajog.2013.08.020

11. Iacovides S, Avidon I, Baker FC. What we know about primary dysmenorrhea today: a critical review. Hum Reprod Update 2015;21(6):762-78 https://doi.org/10.1093/humupd/dmv039

12. Reynolds N, Mrug S, Hensler M, Guion K, Madan-Swain A. Spiritual coping and adjustment in adolescents with chronic illness: a 2-year prospective study. J Pediatr Psychol 2014;39(5):542-51.

https://doi.org/10.1093/jpepsy/jsu011

13. Kelly GA, Blake C, Power CK, O'Keeffe D, Fullen BM. The association between chronic low back pain and sleep. Clin J Pain 2011;27(2):169-81. https://doi.org/10.1097/AJP.0b013e3181f3bdd5

14. Blågestad T, Pallesen S, Lunde L-H, Sivertsen B, Nordhus I-H, Grønli J. Sleep in older chronic pain patients. Clin J Pain 2012;28(4):277-83.

https://doi.org/10.1097/AJP.0b013e3182313899

15. Ishikura IA, Hachul H, Pires GN, Tufik S, Andersen ML. The impact of primary dysmenorrhea on sleep and the consequences for adolescent academic performance. J Clin Sleep Med 1999;277(3):1013-21.

16. Iacovides S, Avidon I, Bentley A, Baker FC. Diclofenac potassium restores objective and subjective measures of sleep quality in women with primary dysmenorrhea. Sleep 2009;32(8):1019-26.

https://doi.org/10.1093/sleep/32.8.1019

17. Keshavarzi F, Mahmoudzadeh F, Brand S, Sadeghi Bahmani D, Akbari F, Khazaie H, et al. Both melatonin and meloxicam improved sleep and pain in females with primary dysmenorr hea results from a double-blind cross-over intervention pilot study. Arch Womens Ment Health 2018;21(6):601-9.

https://doi.org/10.1007/s00737-018-0838-x

18. Sivertsen B, Lallukka T, Petrie KJ, Steingrímsdóttir ÓA, Stubhaug A, Nielsen CS. Sleep and pain sensitivity in adults. Pain 2015;156(8):1433-9.

https://doi.org/10.1097/j.pain.0000000000000131

19. Hailemeskel S, Demissie A, Assefa N. Primary dysmenorrhea magnitude, associated risk factors, and its effect on academic performance: evidence from female university students in Ethiopia. Int J Womens Health 2016;8:489-96.

https://doi.org/10.2147/IJWH.S112768

20. Orhan C, Çelenay ŞT, Demirtürk F, Özgül S, Üzelpasacı E, Akbayrak T. Effects of menstrual pain on the academic performance and participation in sports and social activities in Turkish university students with primary dysmenorrhea: a case control study. J Obstet Gynaecol Res 2018;44(11):2101-9.

https://doi.org/10.1111/jog.13768

21. Banikarim C, Chacko MR, Kelder SH. Prevalence and impact of dysmenorrhea on Hispanic female adolescents. Arch Pediatr Adolesc Med 2000;154(12):1226-9.

https://doi.org/10.1001/archpedi.154.12.1226

22. Dawood MY. Nonsteroidal antiinflammatory drugs and changing attitudes toward dysmenorrhea. Am J Med 1988;84(5 suppl.1):23-9. 
https://doi.org/10.1016/0002-9343(88)90473-1

23. Chantler I, Mitchell D, Fuller A. Actigraphy quantifies reduced voluntary physical activity in women with primary dysmenorrhea. J Pain 2009;10(1):38-46.

https://doi.org/10.1016/j.jpain.2008.07.002

\section{THE IMPACT OF PRIMARY DYSMENORRHEA ON} HEALTH RELATED QUALITY OF LIFE

\section{Krutulyte், L.Varaneckiené}

Keywords: primary dysmenorrhea, quality of life, mental health, sleep, physical activity.

Summary

Primary dysmenorrhea (painful menstruation in the absence of organic pelvic pathology) is one of the most common gynecologi- cal disease. Despite the plethora of scientific evidence about primary dysmenorrhea negative impact on health related quality of life, it is often underestimated or even accepted as a normal part of the menstrual cycle. Influence on mental, physical and social well-being of woman is discussed in this article.

Correspondence to: deimante.krutulyte@stud.1smu.1t

Gauta 2020-04-03

\section{KVIEČIAME PRENUMERUOTI „SVEIKATOS MOKSLŲ” ŽURNALĄ 2020 METAIS!}

Žurnalas „Sveikatos mokslai” (Index Copernicus, EBSCO host (Academic Search Complete), Gale (Academic OneFile), ProQuest (Ulrich's, Summon), Australia (ERA) 2012 Journal List (ERA ID 34962) skirtas visų specialybių gydytojams, slaugytojams ir kitiems specialistams, spausdina mokslinius straipsnius lietuvių, anglų kalbomis. Reikalavimai straipsniams atitinka mokslo leidiniams keliamus reikalavimus. Žurnalas kioskuose neparduodamas. Žurnalą, kuris leidžiamas kartą per du mènesius, galima užsiprenumeruoti visuose Lietuvos pašto skyriuose, taip pat internetu: www.prenumeruok.It Prenumeratos kaina nesikeičia: visiems metams - 36 EUR, šešiems mėnesiams - 18 EUR, keturiems mėnesiams - 12 EUR, dviem mėnesiams - 6 EUR. Prenumeratos kodas: 5348. Žurnalo autoriams straipsnių spausdinimas mokamas. 